\title{
HUBUNGAN ANTARA PENERIMAAN DIRI DENGAN PENYESUAIAN DIRI PADA WANITA BERCADAR
}

\author{
Muh Mustagfirin dan Ruseno Arjanggi* \\ Fakultas Psikologi Universitas Islam Sultan Agung, Jl. Kaligawe Raya, No. 4, Kota Semarang, 50112 \\ E-mail: ruseno@unissula.ac.id
}

\begin{abstract}
Abstrak
Setiap wanita muslimah berhak untuk mendapatkan hak dan kebebasan dalam mengenakan pakaian yang sesuai dengan tuntunan syariat Islam dan tidak bertentangan dengan norma dan nilai-nilai yang berlaku dalam masyarakat dan kebudayaan di Indonesia. Di Indonesia sendiri cadar masih dianggap suatu hal yang tabu dan membuat banyak timbulnya perdebatan, pro-kontra mengenai penggunaan cadar dikalangan masyarakat masih dikait-kaitkan dengan budaya Arab, unsur politis, kelompok ekstrimis dan kelompok radikal. Penelitian ini bertujuan untuk mengetahui hubungan antara penerimaan diri dengan penyesuaian diri pada wanita bercadar. Subjek dalam penelitian ini yaitu muslimah bercadar di Semarang yang berjumlah 120 orang. Teknik pengambilan sampel menggunakan teknik snowball sampling. Pengumpulan data menggunakan skala penyesuaian diri dengan indeks diskriminasi 0,305-0,597 dan $\alpha: 0,884$. Skala penerimaan diri dengan indeks diskriminasi aitem bergerak antara 0,284-0,610 dan $\alpha$ : 0,907. Analisis data pada penelitian ini menggunakan teknik korelasi Product Moment. Berdasarkan hasil analisis statistik diperoleh nilai $r_{\mathrm{xy}}$ : 0,776 dengan taraf signifikansi $p=0,000(p<0,01)$. Hasil penelitian ini menunjukkan bahwa ada hubungan positif antara penerimaan diri dengan penyesuaian diri pada wanita bercadar di Semarang.
\end{abstract}

Kata kunci: penyesuaian diri, penerimaan diri

\section{CORRELATION BETWEEN SELF-ACCEPTANCE AND SELF ADJUSTMENT AMONG VEILED WOMEN}

\begin{abstract}
Every Muslim woman has the right to get the right and freedom to wear clothes that are in accordance with the guidelines of Islamic law and do not conflict with the norms and values that apply in society and culture in Indonesia. In Indonesia, the veil is still considered a taboo subject and has generated a lot of debate, the pros and cons regarding the use of veils among the people are still associated with Arabic culture, political elements, extremist groups and radical groups. This study aims to determine the correlation between self-acceptance and self-adjument in veiled women. The subjects in this study were veiled Muslim women in Semarang, totaling 120 people. The sampling technique uses snowball sampling technique. Data collection uses a scale of adjustment with a discrimination index of 0,305-0,597 and $\alpha$ : 0,884. The self-acceptance scale with item discrimination index moved between 0,284-0,610 and $\alpha$ : 0,907. Analysis of the data in this study used the Product Moment technique. Based on the result of statistical analysis rxy: 0,776 with a significance level of $p=0,000(p<0,01)$. The results of this study indicate that there is a positive relathionship between self-acceptance and self-adjustment in veiled women in Semarang.
\end{abstract}

Keywords: Self-acceptance, self-adjustment 


\section{PENDAHULUAN}

Setiap wanita muslimah berhak untuk mendapatkan hak dan kebebasan dalam mengenakan pakaian yang sesuai dengan tuntunan syariat Islam dan tidak bertentangan dengan norma dan nilainilai yang berlaku dalam masyarakat dan kebudayaan di Indonesia. Indonesia yang merupakan negara dengan basis pemeluk agama Islam terbesar di dunia memiliki aturan yang jelas dan ketat dalam hal berpakaian. Meskipun Islam telah menerapkan aturan yang jelas dalam berpakaian namun terdapat keringanan bagi perempuan yang tengah dalam kondisi tertentu. Bagi muslimah menentukan cara berpakain merupakan salah satu pandangan dalam menjalankan kehidupan beragama. Di Indonesia sendiri cadar masih dianggap suatu hal yang tabu dan membuat banyak timbulnya perdebatan, pro-kontra mengenai penggunaan cadar di kalangan masyarakat masih dikaitkaitkan dengan budaya arab, unsur politis, kelompok ekstrimis dan kelompok radikal. Muslimah yang mengenakan cadar berkeyakinan bahwasannya mengenakan cadar bukan karena ada unsur politis maupun paksaan dari kelompok maupun organisasi tertentu, melainkan karena hadits dan Al Quran yang menyuruh untuk mengenakan cadar.

Abdulla bin Mas'ud radhiallahuanhu, Ibrahim An Nakhai dan Al hasan Al Bashri memaknai (Q.S An-Nur:31) bahwasannya wanita tidak boleh menampakkan perhiasannya kecuali hanya pakaiannya saja.Pendapat dari empat madzhab Hanafi, Hambali, Maliki dan Syafi'l menjelaskan bahwasannya pemakain cadar dianjurkan bagi kaum wanita dan menjadi wajib apabila dikhawatirkan menjadi sebuah fitnah. Terlarang bagi seorang wanita menunjukan wajahnya kepada yang bukan mahrom karena khawatir menjadi sebuah fitnah. Karena jika wajah wanita dinampakkan, lelaki sering kali melihatnya dengan syahwat (Hasyiah 'Alad Durr Al Mukhtaar).Dasar dari ayat dan dalil tersebut digunakan oleh kaum muslimah untuk mengenakan hijab maupun memakai cadar/niqab sebagai wujud ketaatan serta kepatuhan terhadap agama.

Bagi sebagian besar kaum muslimah, mengenakan cadar merupakan sebuah konsekuensi dari proses pembelajaran lebih intens mengenai hakikat perempuan dan kewajiban perempuan dalam Islam. Namun hal tersebut kembali lagi pada kepercayaan serta pandangan masyarakat dilingkungan tempat tinggal mereka. Cadar sendiri seringkali diasosiasikan sebagai salah satu atribut organisasi Islam yang fanatik, garis keras dan fundamental (Ratri, 2011). Hal ini juga didukung tentang berbagai berita terorisme yang menyertakan teks atau visual perempuan yang mengenakancadar yang pada akhirnya timbul stigma-stigma negatif tersebut. Goffman (dalam Scheid \& Brown, 2010). Menyatakan bahwasannya konsep stigma sendiri merujuk pada suatu atribut atau tanda negatif yang disematkan oleh pihak eksternal pada seseorang sebagai suatu hal yang telah melekat pada dirinya. Stigma beterkaitan dengan sebuah fenomena yang terjadi ketika seseorang yang diberi label, stereotip dan separation (pengasingan). Menurut Crocker, dkk. ( dalam Major \& O'brien, 2005), stigma sendiri terjadi karena individu memiliki atribut maupun karakter dari identitas sosialnya namun akhirnya terjadi devaluasi pada konteks tertentu.

Selain dari stigma yang sudah melekat bahwasannya wanita bercadar merupakan pengikut aliran Islamgaris keras serta fundamental, sekarang ini cadar mendapatkanserta menghadapi penolakan teknis terutama yang berkaitan dengan fasilitas dan pelayanan public (Kompasiana, 2018). Hal tersebut dapat dilihat bagaimana UIN Yogyakarta dan IAIN Bukit Tinggi yang melarang mahasiswinya untuk mengenakan cadar di lingkungan kampus. Dengan alasan bahwasannya pemakaian cadar akan 
membatasi komunikasi antara dosen dengan mahasiswa dan meluasnya aliran Islam anti-Pancasila (Pudyanto, 2018).

Faktor terpenting dalam pembentukan persepsi interpersonal adalah petunjuk wajah. Diantara berbagai petunjuk non verbal, petunjuk wajah atau facial adalah yang paling penting dalam hal mengenali perasaan persona stimuli.Ahli komunikasi non verbal, Dale G. Leathers (dalam Rakhmat, 2004) mengemukakan pendapat bahwasannya wajah yang merupakan sumber informasi yang sudah lama menjadi patokan sebuah komunikasi interpersonal. Wajah merupakan alat yang sangat penting dalam menyampaikan sebuah makna (Rahmat, 1991). Dalam hal ini, cadar (niqab) atau penutup wajah yang dipakai oleh seorang muslimah dapat membuat salah satu petunjuk penyampaian makna, yang juga merupakan sebuah identitas seseorang menjadi kabur.

Berbagai fenomena mengenai stigma negatif yang terjadi dalam masyarakat terhadap wanita bercadar atas judgement radikalisme, fanatisme berlebihan akan agama, kurangnya proses sosialisasi dalam lingkungan dan sulitnya dikenali atau kaburnya identitas, membuat wanita bercadar menghadapi berbagai macam permasalahan dan penolakan, baik masalah eksternal (between people) maupun internal (within people) pada diri seorang muslimah (Wijayani, 2008). Konflik yang ada kerap mengharuskan seorang muslimah berhadapan dengan kondisi yang sulit dan menimbulkan pertanyaan mengenai bagaimana proses penyesuaian diri dan penerimaan diri akan stigma negatif yang selama ini beredar dimasyarakat. Sebab, ditengah kondisi yang ada di Indonesia yang merupakan negara dengan mayoritas muslim terbesar didunia diskriminasi mengenai wanita bercadar masih acap kali terjadi.

Banyak kendala yang dialami oleh wanita bercadar dalam melakukan interaksi sosial maupun dalam hal penyesuaian dengan lingkungan, ditengah kondisi tersebut terdapat sebagian dari wanita bercadar yang mampu dalam menerima dan menyesuaiakan diri (Sari \& Nuryoto, 2002). Berdasarkan hasil wawancara pendahuluan peneliti dengan 3 wanita bercadar, dapat disimpulkan bahwasannya wanita yang mengenakan cadar mengalami hambatan dalam beradaptasi, pada awalnya merasa kurang nyaman akan pandangan sinis masyarakat serta perkataan masyarakat mengenainya, terkadang mereka juga belum dapat menerima akan perlakuan negatif serta diskriminatif terhadap dirinya yang menimbulkan wanita bercadar melepas cadarnya untuk sesaat bahkan selamanya.

Hasil penelitian terdahulu yang diperoleh dari penelitian yang dilakukan oleh Faricha H.S., dkk (2014) yang berjudul "Studi Fenomenologi Mengenai Penyesuaian Diri Wanita Bercadar" terkait penyesuaian diri wanita bercadar didaerah Solo, tingkat penyesuaian diri dari ke tiga subjek berbedabeda karena alasan mereka mengenakan cadar dan respon dalam menyesuaikan diri. Subjek 1 mengenakan cadar karena disuruh oleh suami, subjek 2 bercadar karena menganggap mengenakan cadar adalah sebuah kewajiban dan harus mengenakannya, dan subjek 3 mengenakan cadar dikarenakan merasa malu dan risih jika wajahnya nampak dan dilihat orang lain (lelaki). Subjek 1 mengatasi ketidaksiapannya mengenakan cadar dengan lingkungan dengan cara membentuk sikap menghindar dan fokus terhadap mimpinya dalam mengembangkan kreativitas anak. Subjek 2 terus berupaya meyakinkan orang tua dengan mentaati segala perintah dan keinginan orang tuanya namun tetap berpegang teguh terhadap keyakinannya dalam mengenakan cadar. Subjek 2 juga berusaha untuk mandiri dengan memiliki usaha sendiri sehingga terbebas dari tuntutan sosial. Sedangkan subjek 3 melakukan interaksi yang wajar dengan teman-temannya baik laki-laki maupun perempuan, mengenakan pakain yang tidak harus gelap, membaur dan aktif dalam lingkungan 
tempat tinggalnya, serta melakukan pembicaraan dnegan diri sendiri sebagai salah satu cara agar dapat bangkit dari keterpurukan.

Penyesuaian diri merupakan suatu proses yang mencakup tingkah laku serta respon mental, dimana individu berusaha dengan keras untuk mampu mengatasi konflik serta frustasi karena terhambatnya kebutuhan dalam dirinya, sehingga mampu terciptanya sebuah keselarasan dan keharmonisan antara tuntutan dalam diri dan tuntutan dari lingkungan (Schneiders dalam Pramadi, 1996:34). Buchori (2002) menyebutkan bahwa penyesuaian diri terdiri dari 2 aspek, yakni penyesuaian pribadi dan penyesuaian sosial. Penyesuaian pribadi merupakan kemampuan seseorang untuk menerima dirinya, sehingga ia mampu mengatasi konflik, tekanan, dan menjadi pribadi yang matang, bertanggung jawab dan mampu untuk mengontrol diri sendiri. Sedangkan penyesuaian sosial merupakan kemampuan seseorang dalam mematuhi norma dan peraturan sosial yang berlaku, sehinnga mampu untuk menjalin relasi sosial dengan baik dan mampu menyesuaikan diri dengan lingkungan. Dalam penelitian ini penyesuaian sosial berada dalam lingkup hubungan sosial tempat wanita bercadar berinteraksi dan hidup yaitu tempatnya tinggal bersama keluarga maupun lingkungan sekitar.

Penerimaan diri penting dimiliki wanita bercadar karena dengan adanya penerimaan diri mereka lebih yakin dalam menjalani kehidupan sebagai wanita bercadar, memiliki tanggung jawab, dapat menerima kekurangan dan kelebihan, memeiliki kepercayaan diri, menganggap dirinya sama dengan orang lain, hingga mampu dalam menghadapi permasalahan apapun. Penerimaan diri adalah suatu keadaan yang menunjukkan bahwa seorang individu dapat menerima kekurangan dan kelebihan yang dia miliki, menghargai dirinya sendiri, serta memiliki suatu harapan yang sesuai dengan realita menurut Calhoun \& Acocella (dalam Izzati \& Waluya, 2012). Sheerer (dalam Denmark, 1973) menjelaskan bahwasannya individu yang memiliki self acceptance yang baik akan memiliki karakteristik yang bergantung pada nilai-nilai internal, yakin dalam menjalani hidup, mempunyai tanggung jawab, objektik dalam menerima kritik dan pujian, menerima kekurangan dan kelebihan, tidak merasa malu dan menganggap dirinya sama dengan orang lain. Bernard (2013) menyatakan bahwa penerimaan diri terdiri dari 2 aspek, yakni kesadaran diri dan menerima diri sendiri tanpa syarat.

\section{METODE PENELITIAN}

Penelitian ini adalah penelitian kuantitatif dengan populasi yang terdiri dari muslimah bercadar di Kota Semarang. Teknik pengambilan sampel menggunakan snowball sampling dan diperoleh total sampel sebanyak 120 orang dengan rentang usia 16-34 tahun. Metode pengambilan data yang dilakukan adalah metode skala. Skala yang digunakan yaitu skala penerimaan diri dan skala penyesuaian diri. Skala penyesuaian diri yang digunakan disusun berdasarkan aspek penyesuaian pribadi dan aspek penyesuaian sosial menurut Buchori (2002). Sedangkan skala penerimaan diri yang digunakan dalam penelitian ini disusun berdasarkan aspek penerimaan diri menurut Bernard (2013) yaitu kesadaran dan menerima diri tanpa syarat. Skala penerimaan diri terdiri dari 29 aitem yang memiliki koefisien daya beda berkisar 0,284 sampai 0,610 dan estimasi reliabilitas alpha cronbach sebesar 0,907. Skala penyesuaian diri terdiri dari 31 aitem yang memiliki koefisien daya beda aitem berkisar 0,305 sampai 0,597 dan estimasi reliabilitas alpha cronbach sebesar 0,884. Analisis data pada penelitian ini menggunakan teknik korelasi Product Moment dengan bantuan perangkat lunak 
SPSS for Windows Release versi 25.0. Uji reliabilitas dalam penelitian ini menggunakan teknik koefisien Alpha Cronbach dengan program SPSS versi 25.0.

Tabel 1. Indeks Validitas dan Reliabilitas Alat Ukur

\begin{tabular}{llll}
\hline Alat Ukur & Jumlah Item Valid & Indeks Daya Beda & Indeks Reliabilitas \\
\hline Persepsi & 18 & $0,5-0,87$ & 0,936 \\
Kecemasan & 20 & $0,5-0,93$ & 0,929 \\
\hline
\end{tabular}

\section{HASIL}

Penelitian ini dilakukan dengan membagikan skala kepada muslimah yang mengenakan cadar di Kota Semarang. Sebelum melakukan uji hipotesis, uji asumsi normalitas dan linieritas dilakukan terlebih dahulu. Penelitian ini menggunankan teknik One Sample Kolmogorov-Smirnov $Z$ dengan taraf signifikan 0,05 untuk uji normalitas. Suatu data yang memiliki distribusi normal jika memiliki taraf signifikansi lebih besar dari 5\% atau 0,05.

Tabel 2. Hasil Analisis Uji Normalitas

\begin{tabular}{lllllll}
\hline Variabel & Mean & Std. Deviasi & KS-Z & Sig & $\mathbf{P}$ & Ket. \\
\hline Penyesuaian Diri & 104,23 & 8,240 & 0,062 & 0,200 & $\geq 0,05$ & Normal \\
Penerimaan Diri & 96,50 & 9,542 & 0,061 & 0,200 & $\geq 0,05$ & Normal \\
\hline
\end{tabular}

Hasil uji normalitas yang diperoleh dari data penyesuaian diri diperoleh nilai K-SZ sebesar 0,062 dengan taraf signifikansi sebesar $0,200(\rho>0,05)$ hal tersebut menunjukan bahwa persebaran skala penyesuaian diri termasuk normal. Hasil perhitungan uji normalitas yang diperoleh dari data skala penerimaan diri diperoleh dari nilai KS-Z sebesar 0,061 dengan taraf signifikansi sebesar 0,200 $(\rho>0,05)$ hal ini menunjukan bahwa persebaran skala penerimaan diri termasuk normal.

Tabel 3. Hasil Uji Normalitas

\begin{tabular}{|c|c|c|c|}
\hline \multicolumn{4}{|c|}{ One-Sample Kolmogorov-Smirnov Test } \\
\hline & & penyesuaian_diri & penerimaan_diri \\
\hline $\mathrm{N}$ & & 120 & 120 \\
\hline \multirow[t]{2}{*}{ Normal Parameters ${ }^{\mathrm{a}, \mathrm{b}}$} & 104,23 & 96,50 & 104,90 \\
\hline & 8,240 & 9,542 & 9,916 \\
\hline \multirow[t]{3}{*}{ Most Extreme Differences } & 094 & ,063 & 061 \\
\hline & 094 & 063 & 061 \\
\hline &,- 067 &,- 055 &,- 048 \\
\hline Test Statistic & & 094 & ,063 \\
\hline Asymp. Sig. (2-tailed) & &, $011^{\mathrm{c}}$ & $200^{c, d}$ \\
\hline
\end{tabular}
a. Test distribution is Normal.
b. Calculated from data.
c. Lilliefors Significance Correction.
d. This is a lower bound of the true significance.

Tahap selanjutnya dalam uji asumsi adalah uji linieritas, yang bertujuan untuk mengetahui hubungan yang linier antar variabel. Hasil dari uji linieritas digunakan untuk melihat signifikansi 
hubungan antar variabel. Hasil uji linieritas hubungan antara penerimaan diri dengan penyesuaian diri memperoleh nilai $\mathbf{F}_{\text {linier }}=178,503$ dengan $p=0,000(p<0,01)$. Hasil tersebut menujukan bahwa hubungan antara variabel penerimaan diri dengan variabel penyesuaian diri memiliki hubungan yang linier.

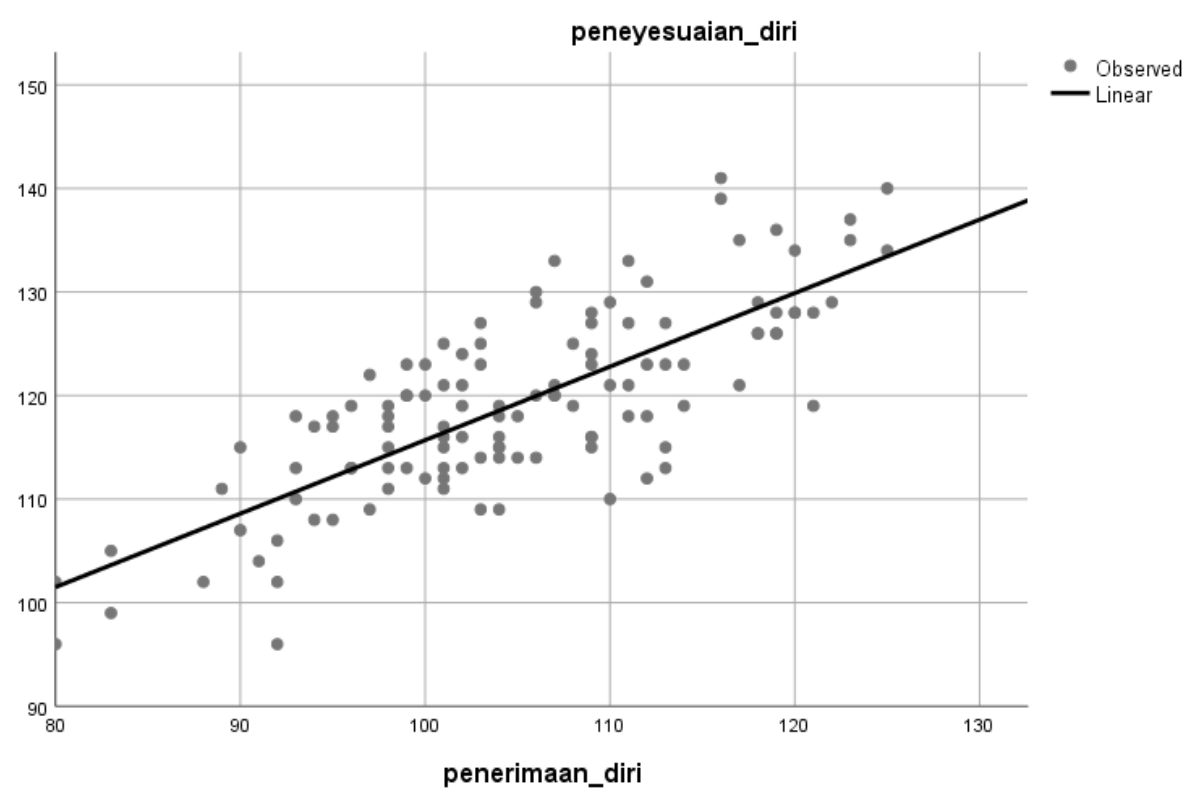

Gambar 1. Kurva Hasil Uji Linieritas

Berdasarkan hasil hipotesis yang dilakukan menggunakan SPSS pada teknik analisis product moment diperoleh nilai $r_{x y}$ sebesar 0,776 dengan taraf signifikansi $p=0,000(p<0,01)$. Hasil tersebut menunjukan bahwa hipotesis diterima yaitu adanya hubungan positif antara penerimaan diri dengan penyesuaian diri wanita bercadar. Semakin tinggi penyesuaian diri yang diterima berbanding lurus dengan penerimaan diri wanita bercadar.

Tabel 4. Hasil Uji Korelasi Pearson

\section{Correlations}

\begin{tabular}{llll}
\hline & & penyesuaian_diri & penerimaan_diri \\
\hline Pearson Correlation & penyesuaian_diri & 1,000 &, 776 \\
& penerimaan_diri &, 776 & 1,000 \\
Sig. (1-tailed) & penyesuaian_diri & $\cdot$ &, 000 \\
& penerimaan_diri &, 000 &. \\
$\mathrm{~N}$ & penyesuaian_diri & 120 & 120 \\
& penerimaan_diri & 120 & 120 \\
\hline
\end{tabular}

Deskripsi hasil penelitian dipergunakan untuk memberikan gambaran mengenai skor skala pada kelompok subjek yang dipakai saat pengukuran. Deskripsi data juga memiliki tujuan yaitu untuk mengetahui informasi mengenai keadaan subjek pada variabel yang diteliti. Kategori subjek pada penelitian ini berdasarkan pada mode distribusi normal. Hal ini berdasar dengan asumsi bahwa skor 
subjek berdistribusi normal. Kategorisasi tersebut bertujuan untuk menempatkan subjek pada kelompok yang sesuain dengan atribut penelitian.

Berdasarkan hasil pengumpulan data menggunakan skala penyesuaian diri, sebanyak $98,3 \%$ subjek memiliki penyesuaian diri dalam kategori sangat tinggi. Sebagian besar subjek, yakni sebanyak $74,2 \%$ juga memiliki penerimaan diri yang berada dalam kategori sangat tinggi. Kategorisasi subjek berdasarkan kedua skala dirinci sebagai berikut:

Tabel 5. Kategorisasi skala penyesuaian diri

\begin{tabular}{llll}
\hline Kategori & Norma & Jumlah Subjek & Persentase \\
\hline Sangat Tinggi & $105,4<x \leq 124$ & 118 & $98,3 \%$ \\
Tinggi & $86,8<x \leq 105,4$ & 2 & $1,7 \%$ \\
Sedang & $68,2<x \leq 86,8$ & 0 & $0 \%$ \\
Rendah & $49,6<x \leq 68,2$ & 0 & $0 \%$ \\
Sangat Rendah & $31<x \leq 49,6$ & 0 & $0 \%$ \\
Total & & $\mathbf{1 2 0}$ & $\mathbf{1 0 0 \%}$ \\
\hline
\end{tabular}

Tabel 6. Kategorisasi skala penerimaan diri

\begin{tabular}{|c|c|c|c|}
\hline Kategori & Norma & Jumlah Subjek & Persentase \\
\hline Sangat Tinggi & $98,6<x \leq 116$ & 88 & $74,2 \%$ \\
\hline Tinggi & $81,2<x \leq 98,6$ & 29 & $24,2 \%$ \\
\hline Sedang & $63,8<x \leq 81,2$ & 2 & $1,7 \%$ \\
\hline Rendah & $46,4<x \leq 63,8$ & 0 & $0 \%$ \\
\hline Sangat Rendah & $29<x \leq 46,4$ & 0 & $0 \%$ \\
\hline \multicolumn{2}{|c|}{ Total } & 120 & $100 \%$ \\
\hline
\end{tabular}

\section{PEMBAHASAN}

Penelitian ini dilakukan dengan tujuan untuk menguji apakah ada hubungan antara penerimaan diri dengan penyesuaian diri wanita bercadar. Hasil uji hipotesis dalam penelitian ini menunjukan bahwa nilai koefisien korelasi $r_{x y}$ sebesar 0,776 dengan taraf signifikansi $p=0,000(p<0,01)$. Hasil tersebut menunjukan bahwa terdapat hubungan positif antara penerimaan diri dengan penyesuaian diri pada wanita bercadar. Hal tersebut menunjukan semakin tinggi penerimaan diri maka semakin tinggi juga tingkat penyesuaian diri wanita bercadar, sebaliknya semakin rendah penerimaan diri maka semakin rendah pula penyesuaian diri wanita bercadar.

Penelitian ini sejalan dengan penelitian terdahulu yang dilakukan oleh Renaldi (2014) bahwa terdapat hubungan antara penerimaan diri dengan penyesuaian diri pada remaja difabel. Hasil penelitian menunjukan bahwa, terdapat hubungan positif yang sangat signifikan antara penerimaan diri dengan penyesuaian diri $(r=0,983, p<0,05)$ hal tersebut mengindikasikan bahwa terdapat pengaruh penerimaan diri dalam penyesuaian diri. Hasil ini sejalan dengan pendapat Calhoun dan Acocella (dalam Carson, 2006) bahwasannya penerimaan diri merupakan aset yang berharga, oleh sebab itu penerimaan diri akan membatu dalam hal penyesuaian diri sehinnga membuat diri lebih seimbang dan terintegritas. Darajat (2006) memaparkan bahwa penerimaan diri adalah suatu faktor yang dapat mempengaruhi proses penyesuaian diri, sebagai bentuk kesadaran dalam menerima diri apa adanya. Sari (2002) memperkuat pendapat bahwa faktor yang mempengaruhi penyesuaian diri adalah penerimaan diri, dimana individu yang memiliki tingkat penerimaan diri yang tinggi akan 
memiliki tingkat kesadaran yang tinggi dalam memandang diri sendiri, sehingga membuat individu memiliki rasa aman dan kepercayaan diri untuk dapat diterima dalam masyarakat.

Hurlock (1991) berpendapat bahwa tingkat penyesuaian diri dipengaruhi oleh penerimaan diri, dimana penerimaan diri yang membantu individu dalam mewujudkan kemampuan dirinya dengan keyakinan bahwa individu mampu menjalani kehidupan, maka individu akan dengan mudah untuk menyesuaikan diri. Diperkuat pendapat Sari (2002) bahwa faktor yang mempengaruhi penyesuaian diri adalah penerimaan diri, dimana individu akan memiliki tingkat kesadaran tinggi dalam memandang dan memahami dirinya. Jika individu tidak mampu dalam menerima dan memenuhi tuntutan lingkungan fisik dan sosialnya maka akan menyebabkan timbulnya perasaan kurang nyaman dan tidak tenang.

Analisis data skala penyesuaian diri menunjukan bahwa dalam penyesuaian diri wanita bercadar berada dalam kategori tinggi. Hal ini dapat diketahui berdasarkan rentang skor mean empirik subjek yang berada pada kategori tinggi yaitu 104,23. Hasil analisis dari skala penerimaan diri menunujukan bahwasaanya penerimaan diri wanita bercadar berada dalam kategori yang tinggi. Hal ini berdasarkan rentang skor mean empirik subjek yang berada pada kategori tinggi yaitu 96,50 . Hal ini menunjukan bahwa hasil penelitian yang dilakukan terhadap wanita bercadar memiliki penyesuaian diri dan penerimaan diri yang tinggi.

\section{KESIMPULAN}

Berdasarkan dari penelitian yang telah dilakukan dapat ditarik kesimpulan bahwa dalam penelitian ini menunjukan tingginya tingkat penyesuaian diri yang dimiliki seseorang dipengaruhi oleh faktor penerimaan diri yang baik pula dan seseorang yang memiliki penerimaan diri yang baik maka orang tersebut memiliki penyesuaian diri yang baik pula. Hasil dari penelitian ini menunjukan terdapat hubungan positif yang signifikan antara penerimaan diri dengan penyesuaian diri wanita bercadar. Wanita bercadar yang memiliki penerimaan diri yang baik maka penyesuaian dirinya baik pula. Sehubungan dengan hasil penelitian yang telah dilakukan, peneliti bermaksud untuk memberi saran kepada wanita bercadar agar selalu berfikir positif dan member apresiasi terhadap diri sendiri agar supaya perilaku yang dihasilkan tetap positif. Kemudian bagi peneliti selanjutnya yang tertarik untuk melakukan penelitian terkait, diharapkan untuk dapat menyertakan variabel lain yang mempengaruhi penyesuaian diri ataupun menambah variabel dan juga subjek dalam penelitian.

\section{DAFTAR PUSTAKA}

Abidin, Ibnu. 1992. Hasyiyah Radd Al-Mukhtar ala Ad-Durr Al-Mukhtar (Beirut:Dar Al-Fikr) Bandung

Aryani, N. D. (2015). Hubungan Orang Tua-Anak, Penerimaan Diri dan Keputusasaan pada Remaja dari Keluarga Broken Home. Jurnal Sains dan Praktik Psikologi, 3(1), 80-90.

Azwar, S. (2013). Metode Penelitian. (Udin,Penyunt.) Yogyakarta, Indonesia: Pustaka Pelajar.

Azwar, S. (2014). Penyusunan skala psikologi. Yogyakarta, Indonesia: Pustaka Pelajar.

Aziz, Sholehudin. 2011. Misteri di Balik Wanita Bercadar.http://ikhlaspurnama36.blogspot.com/2011/05/misteri-di-balik-wanitabercadar_18.html?showComment=1338134487667\#c3514933512652174004. Internet. 
Bernard, M. E. (2013). The strength of self-acceptance: theory,practice and research. New York: Springer.

Damayanti, E. (2015). Peran belajar berdasar regulasi diri dan penyesuaian diri terhadap prestadi belajar siswi Madrasah Tsanawiyah Muallimat Yogyakarta. Jurnal Biotek, 3(2), 54-69.

Dhania, 2009. Hubungan Penyesuaian Diri Dengan Kepercayaan Diri Mahasiswa Baru Universitas Negeri Semarang, Skripsi. Tidak Diterbitkan. Fakultas Psikologi dan Ilmu Pendidikan. Universitas NegeriSemarang:UNS

Denmark, K. L. (1973). Self-acceptance and leader effectiveness. Journel of extension, 6-12

Gerungan, W.A,. 1996. Psikologi Sosial. Bandung: PT Eresco

Gunarsa, S.D. (2006).Psikologi sosial I. Bandung: Eresco.

Hurlock, E. 1996. Psikologi perkembangan.Alih bahasa: suatu pendekatan sepanjang rentang kehidupan. Jakarta : penerbit Erlangga

Hadi, Usman, "Alasan Mahasiswi UIN Yogya Keberatan Larangan Bercadar:Hak Pribadi", Detik News.com, Edisi Senin 05 Maret (2018).

Izzati, A., \& Waluya, O. T. (2012, Desember). Gambaran Penerimaan Diripada Penderita Prosiasi.Jurnal Psikologi, X(2),68-78.

Jalaludin, A. (2018). Tafsir jalalain.Jakarta: Ummul Quro

Kartono, K. 2000. Hygiene Mental. Jakarta : CV. Mandar Maju.

Kusuma, A. W. (2013). Hubungan antara dukungan sosial dan penerimaan diri dengan resiliensi pada remaja penyandang tuna rungu di slb-b kabupaten Wonosobo. Skripsi, abstrak.UNS

Major, B. \& O'Brien, L.T. (2005) The Social Psychology of Stigma. Annual Review of Psychology, 56, 393-421.

Meilinda, E. (2013). Hubungan antara Penerimaan Diri dan Konformitas Terhadap Intensitas Merokok Pada Remaja di SMK Istiqomah Muhammadiyah 4 Samarinda. eJournal Psikologi, I(1), 9-22.

Mu'tadin, Z. 2002. Penyesuaian Diri Remaja. www.e-psikologi.com.

Pramadi, A.1996. Hubungan Antara Kemampuan Penyesuaian Diri Terhadap Tuntutan Tugas Dan Hasil Kerja. Anima. Volume XI. Nomor 43. H.237-245.

Pudyanto, R. (2018). Rektor UIN; Larangan bercadar untuk cegah radikalisme, fundamentalisme. Retrieved March 8, 2018, from http://www.bbc.com/

Rakhmat, Jalaluddin. 2004. Psikologi Komunikasi. Bandung: Remaja Rosdakarya

Ratri, Lintang. (2011). Cadar, Media, dan Identitas Perempuan Muslim. Jurnal ilmiah Forum Universitas Diponegoro: 29-37, No.2.

Retno, Adhe, "Pencerahan dari Sumanto Al Qurtuby tentang Cadar", Kompasiana,Edisi 9 (2018)

Sapto, Hari.(2009). Memahami Makna Jilbab dan Mengkomunikasikan Identitas Muslimah. Universitas Diponegoro. 
Sari, E. P., \& Nuryoto, S. (2002). Penerimaan Diri pada Lanjut Usia Ditinjau dari Kematangan Emosi. Jurnal Psikologi NO. 2, 73-88.

Sartain, A.Q, North, A.J., Strange, J.R., and Chapman, H.M. 1973. Psychology: Understanding Human Behavior. Singapore: McGraw Hill.

Scheid, T. L., \& Brown, T. N. (2010). A Handbook for Study of Mental Health: Social Contexts, Theories, and System. 2nd Edition. New York: Cambridge University Press

Schneiders, A.A. (2008), Personal adjustment and mental health.New York: Holtt. Renchart and Winston Inc.

Sitepu, Mehulika. "Pelarangan cadar di uin sunan kalijaga yogyakarta ditiadakan akibat tekanan sosial?". BBC Indonesia, Edisi 13(2018).

Sugiono. (2014). Metode Penelitian Kuantitatif Kualitatif dan R\&D. Bandung: Alfabeta

Taimiyah, dkk. 2010. Hijab dan Cadar bagi Wanita Muslimah. Yogyakarta : At Tuqa Wardhani,

Wijayani 2008. Psikologi Komunikasi. Gavamedia: Yogyakarta 